\title{
Differences in pre-planned agility and reactive agility performance in sport games
}

\author{
Jaromír Šimonek*, Pavol Horička, and Ján Hianik \\ Faculty of Education, Constantine the Philosopher University in Nitra, Nitra, Slovakia
}

Copyright: (C) 2016 J. Šimonek et al. This is an open access article licensed under the Creative Commons Attribution License (http://creativecommons.org/licenses/by/4.0/).

\begin{abstract}
Background: Authors in their contribution point to the differences in the methods of measurement of agility in the practice. Based on the experience of coaches as well as on their own experience have come to the conclusion that the Illinois Agility Test, which has long been used for the testing of agility in fact does not measure perception abilities and decision-making processes, since motor activity performed during the testing procedure represents a closed skill, where the only task of the tested person is to accelerate, decelerate and change the direction of running, while the task is known in advance. On the contrary, some authors recommend the testing of agility using apparatuses measuring selective reaction, such as Fitro Agility Check. Objective: The aim of the research was to find out differences in the performance of players from the point of view of sport specialization and also to assess the relationship between the performance of players in two agility tests (Illinois Agility Test, measuring the ability of simple reaction, acceleration, deceleration and changes of movement direction, as well as Fitro Agility Check, measuring the above mentioned processes plus the ones of perception and decision-making). Methods: The sample comprised basketball (G1), volleyball (G2) and soccer (G3) players $\left(N=55\right.$ boys, $M_{\text {age }}=15.78$ years, age range $=14-17$ years $)$ from sport clubs in Slovakia. Illinois Agility Test (IAT) was used for testing acceleration and deceleration speed, simple reaction as well as changes of direction. Time of the trial was recorded by Microgate photocells. Fitro Agility Check (FAC) was used for the testing of reactive agility. Differences between independent groups were assessed using Kruskal-Wallis $H$ test, or Mann-Whitney $U$ test. Non-parametric Spearman correlation coefficient was used for detecting whether any correlation between the two variables exists (results in FAC vs IAT). Results: The greatest differences were found between the performances of players in IAT, on the contrary in the test FAC we found agreement in performances of players of different specializations. The value of statistical significance $(p=.774)$ point to the non-existence of a relationship between the performance in IAT vs FAC and stress fundamental difference between both variables. Conclusions: This study provides evidence supporting the experience of coaches that when developing agility it is inevitable to transfer from performing exercises with the change of direction planned in advance realized in static conditions onto the practice of open skills, in which reaction to the changing conditions of the match is combined with anticipation of the resulting optimum solution of the given situation.
\end{abstract}

Keywords: Fitro Agility Check, Illinois Agility Test, soccer, basketball, volleyball, testing

\section{Introduction}

Speed abilities in sport games represent a complex of psychomotor abilities (Verkhoshansky, 1996) involving movement of the body as fast as possible. Agility, however, represents another dimension, which is the change of movement direction (running). Speed abilities are usually defined as movement of an object (athlete's body) in an effort to cover the specified distance

\footnotetext{
* Address for correspondence: Jaromír Šimonek, Department of Physical Education and Sport, Faculty of Education, Constantine the Philosopher University in Nitra, Tr. A. Hlinku 1, 94974 Nitra, Slovakia. E-mail: jsimonek@ukf.sk
}

in the shortest possible time, similarly to cyclic speed, however, without defining the direction of movement (Harman \& Garhammer, 2008). In fact, this issue is much more complex, since speed of movement is not constant during the whole length of trajectory of movement and thus it can be divided into several phases: acceleration, maintaining maximum speed and deceleration (Plisk, 2008). Agility is most frequently defined as a fast change of direction of movement (Altug, Altug, \& Altug, 1987). It can adopt various abilities started from simple frequency of leg movement at running up to a fast change of running direction. Agility comprises a speed component, which is not the most significant 
sign of this ability. However, this basic definition of agility is rather simplified, since currently there exists a more precise definition not comprising solely speed of movement, but also coordination abilities (balance and simple reaction ability) and complex reaction with a choice of responses to permanently changing stimuli from the environs (Plisk, 2008). Měkota (2000) considers agility to be a physical quality, which by its essence belongs among "mixed" abilities. It is determined by the quality of control and analysers, as well as the kind of muscle fibre. Agility is thus superior to speed and coordination abilities (Šimonek, 2013). Recently, this term expressed the ability to change direction or to start and finish the movement as fast as possible (Gambetta, 1996; Parsons \& Jones, 1998). Similar morphologic and biochemic factors of abilities, such as maximum speed, acceleration speed and agility led several authors to consider the above mentioned abilities related and interconnected. On the contrary, Buttifant, Graham, and Cross (2013) did not find statistically significant relationship between direct sprint and agility in two groups of Australian football players. Correlation between agility, acceleration speed and maximum speed was neither found by Little and Williams (2005) in the group of 106 Australian football players. Based on these results the authors came to the conclusion that agility and speed abilities are distinctive and mutually independent motor abilities. Moreover, if they are connected with the performance of sport-related activities, their correlation is even weaker (Young, Benton, Duthie, \& Pryor, 2001). This can be caused also by the fact that training methods of their development are specific for various kinds of speed abilities and therefore minimum transfer of abilities exists between them (Young, McDowel, \& Scarlett, 2001).

Sheppard and Young (2006) assume that speed abilities and agility represent independent qualities of an athlete and therefore their development requires a high degree of neuro-muscular specificity. Components of perception, which form their foundation and also include anticipation and decision-making processes, play also an important role in their development (Young, James, \& Montgomery, 2002). However, they are specific for various kinds of sport and players' positions. According to Šimonek (2013) agility is connected also with various universal components, such as technique of running, optic sensing, experience, etc.

When testing agility we have to take into consideration sudden changes of direction of movement, acceleration and fast stops. This distinct character of movement, which is used mainly in sport games and martial arts, can show evidence of the fact that there are also other running mechanisms implemented than in typical athletic sprints (Sayers, 2000).
Performing changes of direction of movement is relatively independent from the reaching of speed when running in a straight line (Little \& Williams, 2005; Young, Benton, et al., 2001). Acceleration and deceleration are parts of the movements with changes of direction, which form the essence of the manifestation of agility, and therefore they are specific qualities and must be developed in this way (Jeffreys, 2006).

Showing speed and agility in team sports occurs as a response to play like situations (Young, Benton, et al., 2001). This means that perception-action connection and decision making are critical elements for developing the ability to manifest speed prerequisites and ability in the conditions of a match (Gamble, 2013).

There are two basic concepts of agility development in sport games (Bloomfield, Polman, O’Donoghue, \& McNaughton, 2007). The first one represents development of movement mechanisms, where relatively closed skills are applied. For developing agility specialized commercially available training aids (coordination ladders, mini-hurdles, etc.) are used. This concept does not include significant components of decision-making and complex reaction. The other concept represents agility development by means of relatively open skills, where fast changes of movement direction are executed in training conditions, which are not so structured and therefore similar to the ones in matches. This suggests that development of agility in sport games is always important in terms of optimization of sport preparation of players. Coaches should focus on training means used for the development of speed-strength possibilities in anaerobic regime, where adaptation changes occur in consequence of using these means performed in maximum and submaximum zones of intensity of loading.

The aim of the research was to find out differences in the performance of players from the point of view of sport specialization and also to assess the relationship between performances of players in two agility tests (Illinois Agility Test, measuring the ability of simple reaction, acceleration, deceleration and changes of movement direction, as well as Fitro Agility Check, measuring the above mentioned processes plus the ones of perception and decision-making). Based on the statements of Gamble (2013) and Bloomfield et al. (2007), as well as recommendations of Zemková and Hamar (2001) we expect that there is no relationship between the results of these two agility tests employed with young soccer, volleyball and basketball players. 


\section{Methods}

\section{Participants}

The sample comprised male basketball $(\mathrm{G} 1 ; n=11)$, volleyball (G2; $n=12)$ and soccer (G3; $n=32)$ players $\left(N=55, M_{\text {age }}=15.78\right.$ years, age range $14-17$ years $)$ from sport clubs playing in the first junior division in Slovakia. Different counts of players in partial groups were caused by outer circumstances and conditions for the research.

Informed consent was obtained from the parents of the athletes involved in the measurements in advance. The Ethics Commission of the Faculty of Education, Constantine the Philosopher University in Nitra gave approval to the measurements of the athletes for research purposes.

\section{Data collection}

Illinois Agility Test (IAT) (Getchell, 1979) was used for testing acceleration and deceleration speed, simple reaction as well as changes of direction (pre-planned agility) (Figure 1). Tested athletes carried out one measured trial. Time of the trial was recorded by Kit Racetime2 Light Radio photocells (Microgate, Bolzano-Bozen, Italy).

Fitro Agility Check (FAC) (Zemková \& Hamar, 2001) was used for the testing of reactive agility. Sixteen randomly generated stimuli (time interval $2000 \mathrm{~ms}$ ) were displayed alternatively in four different corners of the screen. Task of the tested person was to react as fast as possible and adequately to the stimuli by running over 3 meters and touching by foot the square mat $(35 \times 35 \mathrm{~cm})$ situated on the floor in the particular corner of the delimited area (Figure 2). Time was measured by the computer programme in milliseconds.

\section{Data analysis}

Basic descriptive statistics were used for data processing. Since the normality of distribution of groups was not observed, differences between independent groups were assessed using Kruskal-Wallis $H$ test. Mann-Whitney $U$ test was used for the comparison of medians of two independent groups (among sport games). Estimation of the strength of effect (Effect size) was realized by coefficient $\eta^{2}$ : small effect .01, medium effect .06 , and large effect .14 (Morse, 1999).

Spearman correlation coefficient $\left(r_{\mathrm{s}}\right)$ was used for finding out associations between IAT and FAC. For the verification of null hypothesis the value $p<.05$ was used. Data were processed using Microsoft Excel (Version 2010; Microsoft, Redmond, WA, USA) and SPSS (Version 13; SPSS, Chicago, IL, USA) programmes.

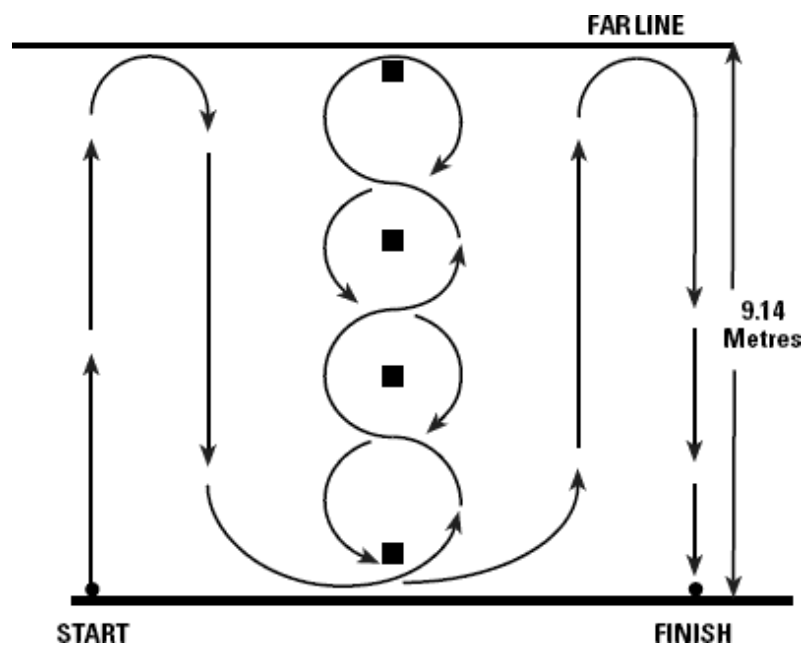

Figure 1. Illinois Agility Test.

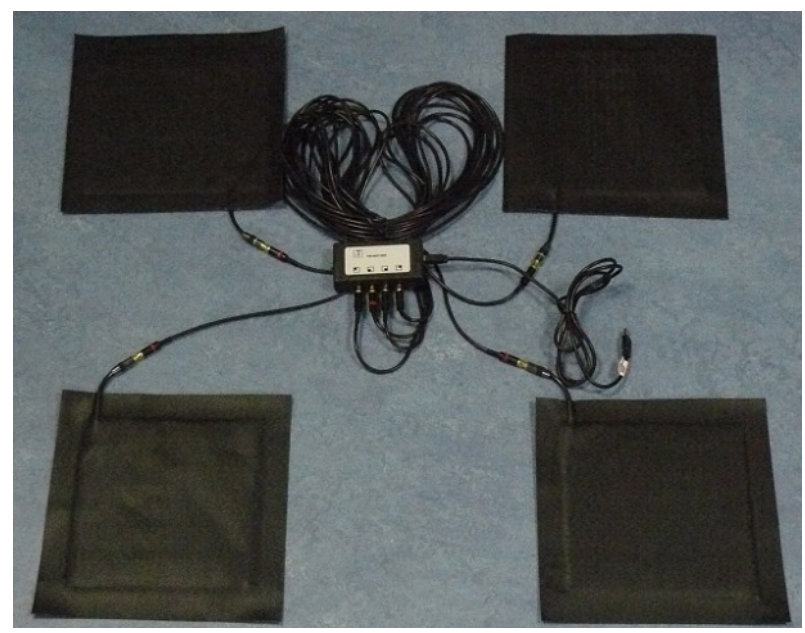

Figure 2. Fitro Agility Check equipment.

\section{Results}

When assessing the level of performances in observed indicators in individual groups (sport games) the following mean values were observed - the highest level of performances in IAT was found in volleyball players $(M=15.76 \mathrm{~s})$, basketball players ranked second $(M=15.79 \mathrm{~s})$ and soccer players ranked third $(M=16.25 \mathrm{~s})$.

By comparing the performances in FAC the highest level of reactive agility was found in the group of soccer players $(M=1287 \mathrm{~ms})$, volleyball players ( $M=1319 \mathrm{~ms}$ ), while the lowest level was recorded in the group of basketball players $(M=1339 \mathrm{~ms})$. Differences in the groups, however, were minimal. Basic descriptive indicators are presented in Table 1.

In IAT statistically significant difference (Table 1) was found between the observed groups of players representing three sport games $(H=10.24 ; p=.006)$. 
Table 1

Descriptive statistics and inter-group differences in Illinois Agility Test and Fitro Agility Check

\begin{tabular}{|c|c|c|c|c|c|c|c|c|}
\hline & $n$ & $M$ & $S D$ & $M d n$ & $I Q R$ & $H$ & $p$ & $\eta^{2}$ \\
\hline \multicolumn{9}{|c|}{ Illinois Agility Test (s) } \\
\hline Basketball & 11 & 15.79 & 0.82 & 15.70 & 0.60 & $10.24^{\mathrm{a}, \mathrm{b}}$ & .006 & .19 \\
\hline Volleyball & 12 & 15.76 & 0.65 & 15.64 & 0.50 & & & \\
\hline Soccer & 32 & 16.25 & 0.40 & 16.25 & 0.54 & & & \\
\hline \multicolumn{9}{|c|}{ Fitro Agility Check (ms) } \\
\hline Basketball & 11 & 1339 & 89 & 1342 & 88 & 2.11 & .348 & .04 \\
\hline Volleyball & 12 & 1319 & 164 & 1285 & 139 & & & \\
\hline Soccer & 32 & 1287 & 82 & 1294 & 101 & & & \\
\hline
\end{tabular}

The found value of effect size points to the large degree $\left(\eta^{2}=.19\right)$ of factor causing the differences between the groups. We can find differentiated level of complex motor abilities between the individual sport games. Basketball players and volleyball players reached a higher level of complex abilities when compared with soccer players $(p<.05)$. Accordingly, inter-group comparison of results in IAT showed statistically significant difference between soccer and volleyball players $(p=.009)$.

By comparing the values of two groups of basketball and volleyball players we found out that there are no differences between performances in both tests (IAT and FAC) ( $p=.877$ and $p=.325$ respectively). In FAC, however, no difference between the groups can be found again ( $p=.895)$. Similar results can be observed also in case of comparing basketball and soccer players. Results in IAT were significantly different in both groups $(p=.013)$; in FAC, however, no difference in performances can be registered again $(p=.140)$.

When assessing the relationship between the two variables (performances in IAT and FAC) in individual sport games the following values were recorded: in basketball $\left(r_{\mathrm{s}}=.527, p=.096\right)$, volleyball $\left(r_{\mathrm{s}}=.273\right.$, $p=.391)$ and $\operatorname{soccer}\left(r_{\mathrm{s}}=.019, p=.918\right)$. No significant relationship $\left(r_{\mathrm{s}}=-.040, p=.774\right)$ was found between both indicators when we included all three sports in the analysis as one group.

\section{Discussion}

The study showed that the FAC discriminates between groups of athletes with different demands on their agility skills. Assessment of the level of performances in the selected indicators using IAT suggested that the observed minimal differences could be caused by different contents of preparation, different genetic prerequisites of players participating in the research, and/or by various stage of sport preparation from the point of view of periodization of loading, characteristics of the structure of movement in the given sport specialization, etc. The highest level of reactive agility was found in the group of soccer players, followed by volleyball and basketball players. This can be attributed to somatic parameters of players in individual sport games (the centre of mass is lower and the movement in joints is faster). With regard to the character of motor performance the dominance of basketball players over volleyball players was expected.

The largest differences between performances thus can be observed in IAT, in which the realization of movement is well known to the player in advance. The stimuli are permanent and static and the degree of decision-making is rather low. In FAC, despite of different sport specialization accordance in performances was found in all comparisons.

When comparing the results in both tests we can see that the highest divergence in performances was observed in IAT. It is obvious that the task of the test is well-known to the athletes in advance. The stimuli are permanent and static and the degree of decision-making is minimal. In the test FAC we found agreement in performances of individual players despite their different specializations in all comparisons. This supports the opinion of Spasic, Krolo, Zenic, Delextrat, and Sekulic (2015) that decision-making processes in sport games are extremely important and our results point to the fact that they determine on the speed of realization of the motor task to a great measure. By the high level of decision-making quality the sportsman can even eliminate deficiencies in the speed of movement when playing the game in sport games. However, 
it is rather from the point of view of time than from the one of the quality of movement realization. Agility in sport games is thus complex motor ability, which requires complex and intentional development through sport training focusing not only on the development of speed abilities, but also more complex processes of reaction and control of movement on a higher level. The measurements carried out by Horička, Hianik, and Šimonek (2014) supported this theory.

Association between FAC and IAT was not proved in any of the groups of players. The two phenomena are not mutually associated, therefore, only few factors in common exist, which would jointly participate in the level of performance in the first and the second tests. This was probably caused by the fact that the character of a sport game has no essential impact on the level of control of the movement, which is limited more by sensori-motor processes on the level of central nervous system than by nerve-muscular, morphological, biological, somatic, or other prerequisites.

Similarly to Sheppard and Young (2006) and Little and Williams (2005) our results stressed the fact that agility is not simply one of speed abilities. Besides simple reaction, acceleration, deceleration in connection with the change of direction speed includes also perception components defined by complex reaction to an unexpected stimulus occurring in variable game situations in sport games. Training of speed abilities and agility requires a high degree of neuro-muscular specificity. Perception components, which form the basis of speed and agility, should then be taken into consideration when developing these qualities including also anticipation and decision-making processes. These facts are specific for individual sports games and players' posts (functions). Manifestation of speed and agility in sport games occurs in reaction to game situations. Therefore these components (action-reaction and decision-making) are the key elements in the development of the ability to manifest speed abilities and agility in the conditions of matches. We agree with Bloomfield et al. (2007) that when developing speed abilities and agility trainers should apply one of the two well-known approaches - the first one comprises training of relatively closed skills, often using specialized (commercially available) aids such as coordination ladders, mini-hurdles, resistance belts, etc. The other approach rests on open skills, where agility is manifested in training conditions, which are less structured and therefore closer to the conditions of matches.

Our study confirmed the findings of Zemková and Hamar (2014) that similar to strength and speed abilities, assessment of agility also requires a sport-specific approach. Experience has shown that the assessment of agility performance under sport-specific conditions represents a more appropriate alternative than the original version of IAT.

\section{Limits of the study}

The authors of the study are fully aware of the following limitations - low number of subjects, low number of sport specializations, and the lack of information on the factors forming the content of agility. The size of the tested group of athletes was rather small, which means that the results may be generalized neither to other sport games, nor to any other sport teams.

\section{Conclusions}

Based on the obtained research data we can conclude that:

- no statistically significant correlations between the performances in FAC and IAT were found;

- results proved the dominance of perception in the character of motor activity in game situations in sport games and its importance at agility development in sport preparation in sport games;

- based on the accomplished research as well as literary sources concerning the paradigm of classification of agility, training and testing, there is a priority coming to our focus and that is the necessity to recognize the essence of the complex physical ability - agility, means of its enhancement, as well as characteristics of existing adequate tests.

As described above, many tests used in the practice, in fact do not comprise the level of agility (thus the processes of decision-making and perception) and should be used just for the measurement of speed abilities to change the direction of movement.

When testing agility it is inevitable to use adequate tests depending on what phenomenon we intend to measure - if we want to measure agility as the ability to accelerate, decelerate and change the direction of movement on static stimuli, we should use IAT, but when we intend to measure also decision-making processes and perception, FAC would be a better diagnostic tool reflecting closer the reality in sport games. Future studies should better explain the structure of agility in both individual and team sports, as well as on a larger sample.

\section{Conflict of interest}

There were no conflicts of interest. 


\section{References}

Altug, Z., Altug, T., \& Altug, A. (1987). A test selection guide for assessing and evaluating athletes. National Strength and Conditioning Association Journal, 9(3), 62-66.

Bloomfield, J., Polman, R., O’Donoghue, P., \& McNaughton, L. (2007). Effective speed and agility conditioning methodology for random intermittent dynamic type sports. Journal of Strength and Conditioning Research, 21, 1093-1100.

Buttifant, D., Graham, K., \& Cross, K. (2013). Agility and speed in soccer players are two different performance parameters. In A. Murphy, T. Reilly, \& W. Spinks (Eds.), Science and Football IV (pp. 229-232). New York, NY: Taylor and Francis.

Gambetta, V. (1996). How to develop sport-specific speed. Sports Coach, 19, 22-24.

Gamble, P. (2013). Strength and conditioning for team sports: Sport-specific physical preparation for high performance (2nd ed.). London, United Kingdom: Taylor and Francis.

Getchell, B. (1979). Physical fitness: A way of life (2nd ed.). New York, NY: John Wiley and Sons, Inc.

Harman, E., \& Garhammer, J. (2008). Administration, scoring, and interpretation of selected tests. In T. R. Beachle \& R. W. Earle (Eds.), Essentials of strength training and conditioning (3rd ed., pp. 250-292). Champaign, IL: Human Kinetics.

Horička, P., Hianik, J., \& Šimonek, J. (2014). The relationship between speed factors and agility in sport games. Journal of Human Sport and Exercise, 9, 49-58.

Jeffreys, I. (2006). Motor learning: Applications for agility, part 1. Strength and Conditioning Journal, 28(5), 72-76.

Little, T., \& Williams, A. G. (2005). Specificity of acceleration, maximum speed and agility in professional soccer players. Journal of Strength and Conditioning Research, 19, 76-78.

Měkota, K. (2000). Definice a struktura motorických schopností (novější poznatky a střety názorů) [Definition and structure of motor abilities (new knowledge and clashes of ideas)]. Čská kinantropologie, 4(1), 59-69.

Morse, D. T. (1999). Minisize 2: A computer program for determining effect size and minimum sample size for statistical significance for univariate, multivariate, and nonparametric tests. Educational and Psychological Measurement, 59, 518-531.

Parsons, L. S., \& Jones, M. T. (1998). Development of speed, agility and quickness for tennis athletes. Strength and Conditioning Journal, 20(3), 14-19.

Plisk, S. (2008). Speed, agility, and speed-endurance development. In T. R. Beachle \& R. W. Earle (Eds.), Essentials of strength training and conditioning (3rd ed., pp. 457-484). Champaign, IL: Human Kinetics.

Sayers, M. (2000). Running techniques for field sport players. Sport Coach, 23, 26-27.

Sheppard, J. M., \& Young, W. B. (2006). Agility literature review: Classifications, training and testing. Journal of Sports Sciences, 24, 919-932.

Šimonek, J. (2013). Niekol'ko poznámok k chápaniu pojmu agilita [Some remarks on understanding the term "agility”]. Telesná výchova a šport, 23(1), 18-23.

Spasic, M., Krolo, A., Zenic, N., Delextrat, A., \& Sekulic, D. (2015). Reactive agility performance in handball: Development and evaluation of a sport-specific measurement protocol. Journal of Sports Science \& Medicine, 14, 501-506.

Verkhoshansky, Y. V. (1996). Quickness and velocity in sports movements. New Studies in Athletics, 11(2-3), 29-37.

Young, W. B., Benton, D., Duthie, G., \& Pryor, J. (2001). Resistance training for short sprints and maximum-speed sprints. Strength and Conditioning Journal, 23(2), 7-13.

Young, W. B., James, R., \& Montgomery, I. (2002). Is muscle power related to running speed with changes of direction? Journal of Sports Medicine and Physical Fitness, 43, 282-288.

Young, W. B., McDowell, M. H., \& Scarlett, B. J. (2001). Specificity of sprint and agility training methods. Journal of Strength and Conditioning Research, 15, 315-320.

Zemková, E., \& Hamar, D. (2001). Posudzovanie disjunktívnych reakčno-rýchlostných schopností [Assessing disjunctive reaction abilities] (1st ed.). Bratislava, Slovakia: Comenius University.

Zemková, E., \& Hamar, D. (2014). Agility performance in athletes of different sport specializations. Acta Gymnica, 44, 133-140. 